\title{
(2) OPEN ACCESS \\ Recanalisation therapies for acute ischaemic stroke in patients on direct oral anticoagulants
}

\author{
David J Seiffge (1) , ${ }^{1,2}$ Thomas Meinel, ${ }^{2}$ Jan Christoph Purrucker (1), ${ }^{3}$

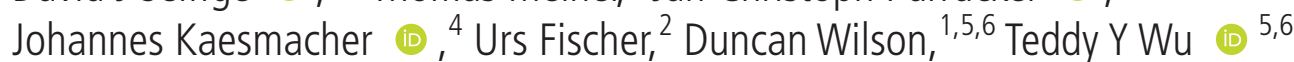

${ }^{1}$ Stroke Research Center, Queen Square Institute of Neurology, London, UK

${ }^{2}$ Department of Neurology, Inselspital University Hospital Berne, Bern, Switzerland ${ }^{3}$ Neurology, Heidelberg University Hospital, Heidelberg, Germany

${ }^{4}$ University Institute of Diagnostic and Interventional of Neuroradiology, University Institute of Diagnostic, Interventional and Pediatric RadiologyUniversity Institute of Diagnostic and Interventional of Neuroradiology, University Institute of Diagnostic, Interventional and Pediatric Radiology, Inselspital, University Hospital Bern, Bern, Switzerland ${ }^{5}$ Neurology, Christchurch Hospital, Christchurch, New Zealand

${ }^{6}$ New Zealand Brain Research Institute, Christchurch, New Zealand

\section{Correspondence to}

Dr David I Seiffge, Neurology and Stroke Center, Inselspita Universitatsspital Bern, Bern 3010, Switzerland; david. seiffge@insel.ch

DW and TYW contributed equally.

Received 25 October 2020 Revised 12 December 2020 Accepted 23 December 2020 Published Online First 4 February 2021

Check for updates

(c) Author(s) (or their employer(s)) 2021. Re-use permitted under CC BY-NC. No commercial re-use. See rights and permissions. Published by BMJ.

To cite: Seiffge DJ, Meinel T, Purrucker JC, et al. I Neurol Neurosurg Psychiatry

2021:92:534-541.

\section{ABSTRACT}

Direct oral anticoagulants (DOACs) have emerged as primary therapeutic option for stroke prevention in patients with atrial fibrillation. However, patients may have ischaemic stroke despite DOAC therapy and there is uncertainty whether those patients can safely receive intravenous thrombolysis or mechanical thrombectomy. In this review, we summarise and discuss current knowledge about different approaches to select patient. Time since last DOAC intake - as a surrogate for anticoagulant activity - is easy to use but limited by interindividual variability of drug pharmacokinetics and long cut-offs (>48 hours). Measuring anticoagulant activity using drug-specific coagulation assays showed promising safety results. Large proportion of patients at low anticoagulant activity seem to be potentially treatable but there remains uncertainty about exact safe cut-off values and limited assay availability. The use of specific reversal agents (ie, idarucizumab or andexanet alfa) prior to thrombolysis is a new emerging option with first data reporting safety but issues including health economics need to be elucidated. Mechanical thrombectomy appears to be safe without any specific selection criteria applied. In patients on DOAC therapy with large vessel occlusion, decision for intravenous thrombolysis should not delay thrombectomy (eg, direct thrombectomy or immediate transfer to a thrombectomycapable centre recommended). Precision medicine using a tailored approach combining clinicoradiological information (ie, penumbra and vessel status), anticoagulant activity and use of specific reversal agents only if necessary seems a reasonable choice.

\section{INTRODUCTION}

Oral anticoagulation using direct oral anticoagulants (DOACs) has emerged as the primary therapeutic option for stroke prevention in patients with non-valvular atrial fibrillation. Furthermore, DOACs are used for treatment of other vascular diseases (ie, intracardiac thrombus, stable coronary heart disease, venous thrombosis) and trials assessing further indications (ie, patent foramen ovale) are ongoing. However, patients may have ischaemic stroke despite DOAC therapy ${ }^{1}$ and recent reports found up to $13 \%$ of all patients who had a stroke to be on anticoagulant therapy prior to stroke onset with rapidly increasing numbers of DOAC. ${ }^{2}$ Intravenous thrombolysis (IVT) and mechanical thrombectomy are the cornerstones of acute stroke therapy to reduce morbidity and improve functional outcome. ${ }^{3} 4$ Acute recanalisation therapies bear the risk of haemorrhagic transformation of the infarcted brain tissue leading to symptomatic intracranial haemorrhage. The rate of symptomatic intracranial haemorrhage ranges between 3.7\% (IVT only), ${ }^{5} 5.1 \%$ (mechanical thrombectomy with thrombolysis) ${ }^{6}$ and $4.3 \%$ (mechanical thrombectomy alone).

In contrast to therapy with vitamin $\mathrm{K}$ antagonists (VKAs) which result in a broad, long lasting unselected inhibition of the coagulation cascade by inhibition of the proper synthesis of several coagulation factors (factors II, VII, IX und X), DOACs directly target selected factors in the coagulation cascade, either thrombin (dabigatran) or factor $\mathrm{Xa}$ (apixaban, rivaroxaban and edoxaban). Onset of the anticoagulatory effect of DOACs is quick (peak levels between 2 and 5 hours after intake) and last only for several hours to a few days. Measuring DOAC activity is challenging ${ }^{8}$ and there are currently no point-of-care devices approved for DOAC measurement. In contrast, monitoring anticoagulant activity in patients taking VKA using point-of-care international normalised ratio (INR) testing is easy and results are rapidly available. ${ }^{9}$ Among patients with DOAC having a stroke, approximately $28 \%$ are potentially eligible for IVT (within 4.5 hours time window, National Institutes of Health Stroke Scale (NIHSS) $\geq 4){ }^{10}$

In analogy to thrombolysis in patients on VKA, current approaches to select patients on DOAC treatment for recanalisation therapies try to identify those patients at low anticoagulant activity to minimise the risk of symptomatic intracranial haemorrhage. Indeed, pioneering studies ${ }^{11-14}$ found that DOAC therapy does not seem to increase the risk of symptomatic intracranial haemorrhage following IVT in such selected patients. Despite this, there remains uncertainty among stroke physicians on how to select such patients. Indeed, in a multicentre German registry study only $6 \%$ of patients on DOACs eligible for thrombolysis received such treatment with DOAC therapy being the reason to withhold thrombolysis in most cases. ${ }^{8}$ In a Swiss study, only $15 \%$ of potentially eligible patients with atrial fibrillation on DOAC therapy received thrombolysis but there seemed to be no barrier to the use of mechanical thrombectomy. ${ }^{8}$ Reflecting the still limited evidence, the American Heart/Stroke Association guidelines do not make strong recommendations on the use of IVT in patients taking DOAC, in fact they state intravenous alteplase may even be harmful unless routine labs or Xa activity 


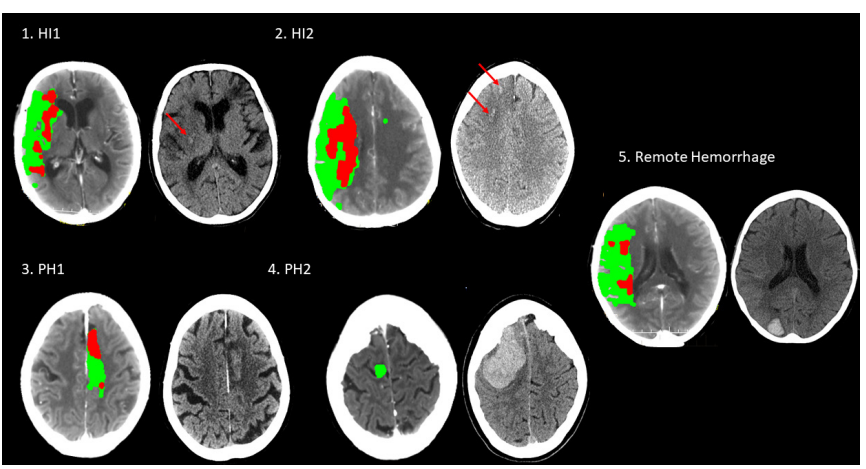

Figure 1 Haemorrhagic transformation on CT ranging from haemorrhagic infaction type I (HI1) to parenchymal haemorrhage type 2 (PH2). Haemorrhagic transformation can occur outside the infarcted brain tissue ('remote haemorrhage'). Left part of each pair CT is the initial perfusion imaging showing infarct core (red) and penumbra (green), and the right part is the postreperfusion $\mathrm{CT}$.

are normal or the patient has not taken a dose in $>48$ hours. ${ }^{15}$ Recent approval of targeted reversal agents for dabigatran (idarucizumab) and apixaban/rivaroxaban (andexanet alfa) offers a new, unprecedented additional option.

In this review, we recapitulate the current understanding of haemorrhagic transformation in acute ischaemic stroke and the role of thrombin, the major treatment target of DOACs, in this process. We present current concepts of patient selection in those taking DOAC and summarise available data for different approaches. Finally, we summarise data on mechanical thrombectomy in patients taking DOAC and whether specific patient selection is warranted.

\section{PATHOPHYSIOLOGY, CLASSIFICATION AND THE ROLE OF THROMBIN IN HAEMORRHAGIC TRANSFORMATION AFTER ACUTE ISCHAEMIC STROKE}

Haemorrhagic transformation of infarcted brain tissue may occur spontaneously after acute ischaemic stroke but acute recanalisation therapies increase the risk. The spectrum of haemorrhagic transformation ranges from scattered small petechiae to large parenchymal bleeding with substantive mass effect (figure 1). Usually, haemorrhagic transformation is classified according to radioclinical criteria developed for large thrombolysis trials (European Cooperative Acute Stroke Study /National Institute of Neurological Disorders and Stroke Trial) using CT imaging and associated worsening of the neurological function (measured using the NIHSS) ranging from haemorrhagic infarction to symptomatic intracerebral haemorrhage (sICH). sICH is associated with substantial mortality and morbidity.

The pathophysiology leading to haemorrhagic transformation is complex. Disruption of the blood-brain barrier increasing vascular permeability plays a major role in haemorrhagic transformation. ${ }^{16}$ The effect of therapeutic anticoagulation on haemorrhagic transformation is probably mediated by increasing the amount of blood extravasation into the infarcted tissue due to reduced blood clotting rather than a direct negative effect on the blood-brain barrier. However, increased thrombin generation during acute ischaemic stroke has toxic effects resulting in blood-brain barrier leakage. ${ }^{17}$ Thrombin inhibition in rodent models exhibits a protective effect on the blood-brain barrier and reduced haemorrhagic transformation. ${ }^{18}$ DOACs either act as direct thrombin inhibitor (dabigatran) or inhibit thrombin generation from prothrombin by inhibiting the action of activated factor X (apixaban, edoxaban, rivaroxaban). Interestingly, a recent phase-II randomised controlled trial assessing the adjunctive use of a direct thrombin inhibitor (agatroban) in addition to IVT shows no increase in the risk of sICH. ${ }^{19}$

VKA, by reducing the amount of factor VII available for interaction with tissue factor (the key system in the initiation of coagulation), ${ }^{20}$ reduces the extrinsic coagulation pathway and subsequent fibrin formation. DOACs do not affect the initial factor VII and VIIa interaction with tissue factor. In rodent models of acute ischaemic stroke and thrombolysis, VKA increased haemorrhagic transformation $^{21}$ whereas dabigatran and rivaroxaban did not increase the risk after thrombolysis in rodent models. ${ }^{22} 23$ In all these experiments, DOAC plasma levels were kept within the expected range during standard therapy (ie, corresponding $<400 \mathrm{ng} / \mathrm{mL}$ in humans). Taken together, there is evidence from animal models that therapeutic anticoagulation with VKA but not DOACs increases the risk of haemorrhagic transformation after ischaemic stroke probably mediated trough the different mode of action and the pivotal role of thrombin inhibition by DOACs. Nevertheless, as direct translation of animal data to human patients is not possible, cautious approaches for clinical practice are warranted.

\section{DRUG MONITORING IN DOACS}

Assessing anticoagulant activity in DOACs in the emergency setting (in analogy to patients taking VKA) is fundamental but not straight forward. ${ }^{24}$ Difficulties include test availability and turn-around time, lack of clear cut-off values and test variability. Conventional, unspecific tests (ie, INR, activated partial thrombin time (aPTT), thrombin time (TT)) along with drugspecific tests have been used to monitor DOAC activity. ${ }^{24}$

Recent systematic reviews ${ }^{24}$ and the latest International Committee for Standardization in Haematology and International Committee on Thrombosis and Haemostasis recommendations ${ }^{25}$ can be summarised as follows: (1) prothrombine time $(\mathrm{PT}) / \mathrm{INR}$ and aPTT are not reliable tests to assess DOAC concentration, (2) current non-specific point of care testing lacks responsiveness to detect DOAC presence and (3) tandem mass spectrometry remains the gold standard; however, drugcalibrated dilute thrombin time, ecarin chromogenic assay, ecarin clotting time, anti-FIIa and anti-FXa are suitable for rapid quantitation of DOACs.

Although not recommended, some information can be derived from unspecific coagulation tests: a normal TT can rule out relevant concentrations of dabigatran. ${ }^{26}$ Anti-Xa inhibitors show some degree of correlation with aPTT and PT/INR; however, results are hampered by overall poor correlations, significant reagent dependent sensitivities and variability within assays. ${ }^{26}$ Studies in patients with acute stroke show similar results with normal aPTT and INR in $11 \%-44 \%$ of patients with peak DOAC drug levels. ${ }^{8}$

Mass spectrometry measurements are considered the gold standard as drug-specific assays for DOAC measurement ${ }^{25}$ but it is unsuitable for emergency situation. Outside of mass spectrometry, only ecarin clotting time (for dabigatran) and calibrated anti-Xa assays (for Xa-inhibitors) show linear correlations to serum levels in a dose-dependent fashion. ${ }^{26}$ These assays have been used to safely guide thrombolysis and thrombectomy but are largely based on expert opinion and pilot safety data. ${ }^{27-29}$

Turnaround time of specific assays is improving. In centres where these assays are used for selection of patients for thrombolysis, results can be available as soon as within $30 \mathrm{~min}^{29}$ There are several new approaches (including urine dipstick and a 
Table 1 Characteristics of different direct oral anticoagulants

\begin{tabular}{|c|c|c|c|c|}
\hline & Dabigatran & Rivaroxaban & Apixaban & Edoxaban \\
\hline Half-life & 13 hours & 5-13 hours & 12 hours & 12 hours \\
\hline Time to peak & 1.5-3 hours & $2-3$ hours & 3-4 hours & $1-2$ hours \\
\hline Oral bio-availability & $3 \%-7 \%$ & $80 \%-100 \%$ & $50 \%$ & $60 \%$ \\
\hline Renal clearance & $80 \%$ & $70 \%$ & $45 \%$ & $50 \%$ \\
\hline Conventional tests & $\begin{array}{l}\text { Normal thrombin time }=\text { no dabigatran circulating. Other } \\
\text { tests not useful. }\end{array}$ & Not useful & Not useful & Not useful \\
\hline Suggested assays & Dilute thrombin time or ecarin-based clotting assays & Calibrated anti-Xa assays & Calibrated anti-Xa assays & Calibrated anti-Xa assays \\
\hline Reversal agents & $\begin{array}{l}\text { Idarucizumab (approved for use prior to urgent } \\
\text { interventions) }\end{array}$ & \multicolumn{2}{|c|}{$\begin{array}{l}\text { Andexanet alfa } \\
\text { (no approval for urgent interventions) }\end{array}$} & $\begin{array}{l}\text { (Andexanet alfa not yet } \\
\text { approved) }\end{array}$ \\
\hline
\end{tabular}

modification of thromboelastography testing incorporating an anti-Xa assay and an ecarin clotting time into a cartridge) but their relevance in acute stroke care is currently not clear. Most promising, an investigator led prospective study investigating a point of care DOAC device (ClinicalTrials.gov Identifier: NCT02825394) has recently been completed and publication of the final results is eagerly awaited. Bed-side testing of relevant concentrations $>30 \mathrm{ng} / \mathrm{mL}$ has shown acceptable sensitivity and specificity for rivaroxaban and edoxaban, as well as dabigatran, by using the Hemochron Signature Elite system. ${ }^{2}$ Finally, as prior studies found that Roche CoaguChek showed good calibration with one DOAC (rivaroxaban) ${ }^{30}$, it seems that the manufacturer is currently working on an evidence-based extension claim.

Lastly, the availability of these specific tests is very limited with only $1.5 \%$ and $22 \%$ of Australasia and North America coagulation laboratories having access, respectively. ${ }^{3132}$ However, 18 of the 20 certified stroke units in Switzerland have access to specific tests for patients who had a stroke with comparable safety results and treatment metrics. ${ }^{33}$

\section{PATIENT SELECTION AND CURRENT GUIDELINE RECOMMENDATIONS}

Different approaches have been proposed including time since last DOAC intake, ${ }^{34}$ drug monitoring using unspecific (ie, INR) ${ }^{2}{ }^{30}$ or drug-specific coagulation assays (ie, DOAC plasma levels) ${ }^{28}$ or the use of specific reversal agents (ie, idarucizumab for dabigatran and andexanet alfa for factor Xa inhibitors) ${ }^{35-37}$ to neutralise DOAC activity. Table 1 provides an overview on different DOACs and their characteristics.

Current guideline recommendations from national and international associations differ significantly in their conclusions (see table 2). The Japanese consensus statement recommends the use of recombinant tissue Plasminogen Activator (rt-PA) with a dosage of $0.6 \mathrm{mg} / \mathrm{kg}$ according to local guidelines. ${ }^{38}$

\section{NON-SELECTIVE APPROACH TO IVT}

There is a considerable number of case reports on patients receiving thrombolysis for acute ischaemic stroke despite being on DOAC therapy (over 40 case reports with $>50$ patients) with 3 patients having sICH after thrombolysis which has been summarised in a recent review. ${ }^{39}$ However, case reports are subject of selection and publication bias. Furthermore, general laboratory coagulation profile appeared to be part of eligibility assessment in several studies but the approach to selection was often not clearly reported. Table 3 provides an overview on available observational data including all studies with more than five patients on DOAC (first paragraph 'heterogeneous or unknown selectin criteria': 5 studies with 475 patients). In a Japanese national cohort, 76 patients on DOACs received IVT (15 also had additional mechanical thrombectomy) without any

Table 2

American Heart/Stroke Association ${ }^{65}$

The use of intravenous alteplase in patients taking direct thrombin inhibitors or direct factor Xa inhibitors has not been firmly established but may be harmful. Intravenous alteplase should not be administered to patients taking direct thrombin inhibitors or direct factor

Xa inhibitors unless laboratory tests such as aPTT, INR, platelet count, ecarin clotting time, thrombin time or appropriate direct factor Xa activity assays are normal or the patient has not received a dose of these agents for $>48$ hours (assuming normal renal metabolising function).

Japanese consensus statement ${ }^{38}$ For dabigatran IVT is not recommended if aPTT $>1.5$ times or last dose is $<4$ hours. In this case, IVT can be considered after intravenous administration of idarucizumab.

For factor Xa inhibitors IVT is not recommended if INR exceeds at least 1.7 .

IVT is not recommended if the time of the last dose is $<4$ hours

IVT can be considered if the time of the last dose is $\geq 4$ hours and the level of INR is $\leq 1.7$ ).

IVT after emergent reversal of prolonged INR using antidotes for other anticoagulants is not recommended.

ESO Karolinska Stroke Update $2018^{66}$

Patients with acute ischaemic stroke under VKA or DOAC treatment with proven large vessel occlusion should be offered IVT (if feasible) and endovascular treatment (thrombectomy).

Thrombolysis allowed if DOAC plasma levels $<30 \mathrm{ng} / \mathrm{mL}$

If no DOAC plasma levels available, INR measurement using Hemochron Signature Elite is possible under specific circumstances

French Society of Vascular Neurology $y^{40}$ IVT if no intake $>48$ hours or DOAC level $<50 \mathrm{ng} / \mathrm{mL}$.

Conventional testing with TT, aPTT, PT and anti-Xa levels may be used (DOAC dependant). In the case of Dabigatran, reversal with Idaracizumab may also be considered.

Australian guidelines

Comparable to French Society of Vascular Neurology

(https://informme.org.au/en/Guidelines/Clinical-

Guidelines-for-Stroke-Management)

aPTT, activated partial thrombin time; DOAC, direct oral anticoagulant; INR, international normalised ratio; IVT, intravenous thrombolysis; PT, prothrombine time; TT, thrombin time; VKA, vitamin $\mathrm{K}$ antagonist. 
Table 3 Observational studies including patients on direct oral anticoagulant (DOAC) treated with intravenous thrombolysis

\begin{tabular}{|c|c|c|c|c|c|}
\hline Study & $\begin{array}{l}\text { Number of patients } \\
\text { (DOAC type) }\end{array}$ & $\begin{array}{l}\text { Number of sICH/ } \\
\text { rate }\end{array}$ & $\begin{array}{l}\text { Number of patients } \\
\text { (comparator) }\end{array}$ & Number of sICH/rate & Comment \\
\hline \multicolumn{6}{|c|}{ Heterogenous or unknown selection criteria ( $n=5$ studies, $n=475$ patients) } \\
\hline Xian et $a l^{12}$ & 251 (all DOAC) & $12(4.8 \%)$ & 1500 (VKA) & $73(4.9 \%)$ & $\begin{array}{l}\text { No selection criteria or information on } \\
\text { anticoagulation available }\end{array}$ \\
\hline Seiffge et $a l^{11}$ & 78 (all DOAC) & $2(3.9 \%)$ & $\begin{array}{l}441 \text { (VKA) and } 8938 \text { (no } \\
\text { anticoagulation) }\end{array}$ & $9.3 \%$ and $7.2 \%$ & $\begin{array}{l}\text { Heterogenous selection criteria, all within } \\
48 \text { hours, partly plasma level-based }\end{array}$ \\
\hline Suzuki et al ${ }^{10}$ & 71 (all DOAC) & $2 \%$ & $\mathrm{n} / \mathrm{a}$ & $\mathrm{n} / \mathrm{a}$ & $\begin{array}{l}\text { National survey and case collection, } \\
\text { (dosage of rt-PA: } 0.6 \mathrm{mg} / \mathrm{kg} \text { ) }\end{array}$ \\
\hline Shahjouei et $a^{14}$ & 6 (dabigatran) & 0 & $\mathrm{n} / \mathrm{a}$ & $\mathrm{n} / \mathrm{a}$ & Case collection \\
\hline Meinel et $a l^{33}$ & 69 (all DOAC) & $3.1 \%$ & $\begin{array}{l}1544 \text { (no anticoagulation) and } \\
156 \text { (VKA with INR <1.7) }\end{array}$ & $3.6 \%(n o)$ and $4.6 \%(V K A)$ & $\begin{array}{l}18 \text { of } 23 \text { centres used DOAC plasma levels } \\
\text { for patient selection }\end{array}$ \\
\hline \multicolumn{6}{|c|}{ DOAC plasma-level based approach ( $n=3$ studies, $n=36$ patients) } \\
\hline Marsch et $a l^{46}$ & 9 (all DOAC) & $1(4.2 \%)$ & 31 VKA & $1(3.3 \%)$ & All patients $<48$ hours of last intake \\
\hline Seiffge et $a l^{28}$ & 18 (rivaroxaban) & 0 & $\mathrm{n} / \mathrm{a}$ & $\mathrm{n} / \mathrm{a}$ & \\
\hline Purrucker et al ${ }^{8}$ & 9 (all DOAC) & 0 & $\mathrm{n} / \mathrm{a}$ & $\mathrm{n} / \mathrm{a}$ & \\
\hline \multicolumn{6}{|c|}{ Idarucizumab ( $\mathrm{n}=8$ studies, $\mathrm{n}=236$ patients) } \\
\hline Beharry et al & 13 (dabigatran) & 0 & $\mathrm{n} / \mathrm{a}$ & $\mathrm{n} / \mathrm{a}$ & Tenecteplase \\
\hline Barber et al & 51 (dabigatran) & $2(3.9 \%)$ & 1285 (all non-DOA) & $49(3.8 \%)$ & \\
\hline Kermer et al & 80 (dabigatran) & 0 & $\mathrm{n} / \mathrm{a}$ & & \\
\hline Küpper et al & 7 (dabigatran) & 0 & $\mathrm{n} / \mathrm{a}$ & & \\
\hline Pretnar Oblak et al & 11 (dabigatran) & $2 \mathrm{sICH}(18.2 \%)$ & $\mathrm{n} / \mathrm{a}$ & no & 9 with elevated thrombin time \\
\hline Giannandrea et al & 55 (dabigatran) & $3 \mathrm{sICH}(5.5 \%)$ & $\mathrm{n} / \mathrm{a}$ & $\mathrm{n} / \mathrm{a}$ & \\
\hline Sanak et al & 13 (dabigatran) & $\begin{array}{l}1 \mathrm{sICH}(7.6 \%) \\
2 \mathrm{alCH}\end{array}$ & $\mathrm{n} / \mathrm{a}$ & $\mathrm{n} / \mathrm{a}$ & \\
\hline Fang et al & 6 (dabigatran) & 0 & $\mathrm{n} / \mathrm{a}$ & $\mathrm{n} / \mathrm{a}$ & \\
\hline
\end{tabular}

INR, international normalised ratio; sICH, symptomatic intracerebral haemorrhage; VKA, vitamin K antagonist.

sICH within 24 hours of treatment. ${ }^{10}$ In this cohort, IVT with rt-PA was used with a dosage of $0.6 \mathrm{mg} / \mathrm{kg}$. Similarly, in the Get With the Guidelines Stroke registry, the sICH rate was $4.8 \%$ (12 patients from 251 patients on DOACs who received IVT). However, time since last DOAC intake was up to 7 days in this study. ${ }^{12}$ An international collaboration of European and Japanese stroke centres published data of 78 DOAC patients (rivaroxaban=47) treated with IVT. Although nearly half $(23 / 47)$ of the rivaroxaban patients recommended for IVT on the basis of low plasma rivaroxaban level $(<100 \mathrm{ng} / \mathrm{mL}),{ }^{11}$ many patients were selected using different approaches and no conclusion about one single selection criterion can be drawn from this study. The overall reported rate of sICH in this study was $2 \%(2$ patients) and none of the patients selected using DOAC plasma levels had sICH. Data from the Swiss Stroke Registry of 69 patients on DOACs receiving IVT found no increased risk of sICH compared with patients without anticoagulation and those on VKAs with INR $\leq 1.7^{33}$ (18 of 23 centres used DOAC plasma levels for patient selection).

\section{SELECTION BY TIME SINCE LAST INTAKE}

The predictable pharmacokinetics and dynamics of DOACs (table 1) has made time since last intake the basis of most guidance for patient selection although based on limited evidence. ${ }^{113440}$ Time since last dose of greater than 48 hours has generally been considered a safe time frame for intervention as this represents approximately four half-lives. However, evidence suggests time since last intake can be a poor correlate for drug activity measured on admission in patients who had a stroke using a drug-specific coagulation assay. ${ }^{41}$ Furthermore, intrinsic (age, renal function, genetic polymorphisms) and extrinsic (drug interactions and metabolism) factors together with drug dosage (once daily vs twice daily) all lead to large interperson variability in DOACs plasma concentrations. ${ }^{26} 42$ Four small observational studies suggest recanalisation therapies (both IVT and endovascular) may be safe in patients taking DOACs within 48 hours of stroke but total numbers are small and subgroup analysis (time from last drug intake 0-4 hours, 5-12, 12-24 etc) not possible. $^{1143-45}$

\section{SELECTION OF PATIENTS BY DRUG MONITORING}

Table 3 summarises observational studies applying DOAC plasma levels to select patients for thrombolysis (middle paragraph, 'DOAC plasma level based approach': 3 studies with 36 patients). However, prior to reviewing the evidence, one needs to understand the complexities in the interpretation of drug monitoring in DOACs (see section on drug monitoring of DOACs).

A single centre study from Basel (Switzerland) reported IVT in 18 patients on rivaroxaban (3 with additional mechanical thrombectomy) using a standard operating procedure with predefined cut-offs for thrombolysis. IVT was given in patients with low $(<20 \mathrm{ng} / \mathrm{mL})$ or intermediate $(20-100 \mathrm{ng} /$ $\mathrm{mL}$ ) levels of rivaroxaban and prior ingestion within 48 hours. ${ }^{28}$ There were no patients with sICH or systemic haemorrhage. A single-centre study from Erlangen (Germany) similarly used predefined plasma DOAC levels for all four available DOACs in determining whether patients were eligible (level $<50 \mathrm{ng} / \mathrm{mL}$ ) or potentially eligible $(50-100 \mathrm{ng} / \mathrm{mL})$ for IVT. ${ }^{46}$ In this report, 24 DOAC (apixaban 9, dabigatran 9, rivaroxaban 6) patients received IVT with 1 case $(4.2 \%)$ of sICH developing in a patient who also had mechanical thrombectomy. In both studies, the median turn-around time for DOAC plasma levels (ie, time from blood sampling to first results) was 39 and $37 \mathrm{~min}$, respectively. ${ }^{2846}$ In a German multicentre study, among 150 potentially eligible patients, only 9 patients received IVT based on DOAC plasma levels without any $\mathrm{sICH} .{ }^{8}$ Although measuring DOAC 
plasma levels is theoretically time consuming, if blood is drawn directly on admission and analysis started immediately, this can be done in parallel to other tasks (obtaining NIHSS, neuroimaging). Therefore, in centres who use this approach in routine, door-to-needle times in patients selected using plasma levels are reasonable 28294647 (eg, 37-48 min) and not significantly delayed compared with patients on VKAs. ${ }^{48}$ Point-of-care testing using CoaguCheck to rapidly detect $<30 \mathrm{ng} / \mathrm{mL}$ (for rivaroxaban ${ }^{30}$ ) takes only less than $1 \mathrm{~min}$.

\section{USE OF SPECIFIC REVERSAL AGENTS PRIOR TO ACUTE TREATMENT}

There are three known reversal agents to DOACs, two available (idarucizumab and andexant alfa) and one under development (and not part of this review).

Idarucizumab is a humanised monoclonal antibody fragment with 350 times the affinity for dabigatran than dabigatran has for thrombin. Andexanet alfa is a recombinant human FXa variant which has an affinity to anti-Xa medications similar to native $\mathrm{Xa}$ itself, serving as a decoy. Both medications have been shown to reverse DOAC activity in a dose-dependent manner from phase 2 trials and have been used in single arm, unblinded observational studies in patients with major bleeding ${ }^{49}$ or major bleeding or need for urgent intervention with return to normal drugspecific activity measures (ie, anti-Xa activity) parameters within minutes. ${ }^{50}$ Idarucizumab has been approved by the European Medical Agency in 2015 to reverse dabigatran and andexanet alfa received conditional approval in 03/2019 for reversing rivaroxaban and apixaban (edoxaban not yet approved, preliminary data available ${ }^{51}$ ). While andexanet alfa has not been approved for the use prior to IVT or mechanical thrombectomy as part of the current license, idarucizumab can be used according to its license for 'patients in urgent need of intervention.'

There is a considerable number of case-reports ( 25 case reports including 31 patients) and one large case series (80 patients) ${ }^{52}$ using idarucizumab prior to IVT. Table 3 provides an overview about currently available data from observational studies (bottom paragraph, 'Idarucizumab': 8 studies including 236 patients) using idarucizumab, including national and hospital based data from continental Europe, ${ }^{52-55}$ New Zealand ${ }^{35} 37$ and Taiwan. ${ }^{56}$ Idarucizumab $5 \mathrm{~g}$ infusion was administered without waiting for confirmation of postreversal normalisation of coagulation profile. The New Zealand national reperfusion registry compared data of patients with dabigatran reversal to non-anticoagulated patients with almost identical risk of symptomatic intracranial haemorrhage in dabigatran $(3.8 \%)$ versus non-anticoagulated patients. ${ }^{35}$ However, idarucizumab is costly (approximately US\$2400) and the cost-benefit of this approach in IVT is currently unknown; decision to treat such patients needs to be individualised.

Andexanet alfa is a novel antidote for factor $\mathrm{Xa}$ inhibitors and provides a rapid but non-permanent reversal of anticoagulant effect. Andexanet alfa is given as a bolus and followed by a 2 hours infusion and anti-Xa activity is reduced by $\sim 90 \%$. However, a rebound of Xa activity occurs following completion of infusion. Treatment is associated with $10 \%$ early thrombotic complications. There is one recent case report describing the use of andexanet alfa prior to thrombolysis in a patient with ischaemic stroke and recent intake of apixaban without bleeding or thrombotic complications. ${ }^{57}$ The current price for andexanet alfa is approximately US\$17 570. A calibrated anti-Xa level to assess DOAC activity costs about SFr45 in Switzerland (approximately US\$50).

\section{MECHANICAL THROMBECTOMY}

Data regarding safety and efficacy of mechanical thrombectomy in patients on DOAC rely on observational studies (table 4; 14 studies with 558 patients). A recent meta-analysis, that also includes patients on VKA, concluded that patients on VKA (sOR $1.6,95 \%$ CI 1.2 to 2.2 ), but not patients on DOAC (sOR $1.0,95 \% \mathrm{CI} 0.6$ to 1.8$)$, had an increased risk of symptomatic intracranial haemorrhage after mechanical thrombectomy as compared with control patients without anticoagulation. ${ }^{48}$ Major limitations of the studies included different rates of IVT (prior to mechanical thrombectomy), lack of reliable assessment of activity of DOAC, inclusion of patients with subtherapeutic DOAC, missing information on DOAC reversal as well as lack of adjustment for confounding. Nevertheless, the association with increased rates of symptomatic intracranial haemorrhage remained stable after including only studies with confirmed therapeutic VKA therapy (sOR $1.7,95 \%$ CI 1.04 to 2.6) with no significant association for patients on confirmed therapeutic DOAC therapy (sOR 1.1, 95\% CI 0.4 to 2.8). Additionally, after adjustments in a large observational study, the association of VKA with symptomatic intracranial haemorrhage (aOR 2.6, 95\% CI 1.3 to 4.8 ) remained tangible without a safety signal in patients on DOAC (aOR 0.9, 95\% CI 0.3 to 3.3 ).

From a technical point of view, mechanical thrombectomy procedures seem feasible and successful in patients on DOAC. In a French multicentre observational study, ${ }^{58}$ an increased rate of successful reperfusion (modified treatment in cerebral ischemia score $2 \mathrm{~b} / 3$ ) in patients on DOAC as compared with patients on VKA $(92.0 \%$ vs $74.3 \%$, p 0.001) was reported. This was confirmed by another study showing that large vessel occlusion in patients on DOAC yielded excellent reperfusion rates as compared with VKA and controls (93.2\% vs $81.5 \%$ vs $84.2 \%) .{ }^{48}$ The pathophysiology underlying this is unclear; however, potential differences in thrombus histology due to the different pharmacologic properties could explain these findings. The complication rates and procedure duration were comparable across the groups. ${ }^{48}$ All patients with large vessel occlusion qualifying for mechanical thrombectomy should be transferred to a centre where this procedure is available. Indication for IVT in patients on DOAC should not unnecessarily delay the transfer.

\section{EXPERT OPINION-BASED APPROACH}

Based on the available evidence, an individualised approach combining monitoring anticoagulant activity, imaging-based selection of patients most likely to benefit from acute recanalisation therapies (ie, mechanical thrombectomy for any large vessel occlusion, IVT in the presence of potentially salvageable tissue) and the use of specific reversal agents only in selected patients seems the most promising approach. Figure 2 outlines these approaches.

\section{FUTURE DIRECTIONS}

Future research needs to elucidate the following aspects: first, availability of DOAC monitoring needs to be improved. Streamlining central laboratory measurement and reducing turnaround times seem feasible. ${ }^{47}$ Point-of-care measurement for DOACs should be among the top priorities. Second, although prior reversal of anticoagulation using a specific reversal agent seems to be a reasonable and safe approach, health economics (pricing) and advanced imaging selection (salvageable tissue) given the relatively small effect size of thrombolysis on functional outcome should be considered. It seems unlikely that this approach should be generalised to all patients. Furthermore, 
Table 4 Observational data on symptomatic intracerebral haemorrhage (sICH) risk following endovascular stroke treatment

\begin{tabular}{|c|c|c|c|c|c|}
\hline Study & $\begin{array}{l}\text { Number of patients } \\
\text { (DOAC type) }\end{array}$ & $\begin{array}{l}\text { Number of sICH/ } \\
\text { rate }\end{array}$ & $\begin{array}{l}\text { Number of patients } \\
\text { (comparator) }\end{array}$ & $\begin{array}{l}\text { Number of sICH/ } \\
\text { rate }\end{array}$ & Comment (DOAC group) \\
\hline \multicolumn{6}{|c|}{ Heterogenous or unknown selection criteria ( $n=14$ studies, $n=558$ patients) } \\
\hline Seiffge et $a l^{11}$ & 27 (all DOAC) & $0(0 \%)$ & $\begin{array}{l}27 \text { (VKA) and } \\
43 \text { no anticoagulation) }\end{array}$ & $\begin{array}{l}6(22 \%) \text { and } \\
2(5 \%)\end{array}$ & $\begin{array}{l}\text { Heterogenous selection criteria, all within } 48 \\
\text { hours, partly plasma level based. }\end{array}$ \\
\hline Rebello et $a l^{45}$ & 17 (all DOAC) & $3(18 \%)$ & $\begin{array}{l}29 \text { (VKA) and } \\
265 \text { no anticoagulation) }\end{array}$ & $\begin{array}{l}5(17 \%) \text { and } \\
27(10 \%)\end{array}$ & $\begin{array}{l}\text { All within } 24 \text { hours; PH1, PH2 and SAH defined } \\
\text { as sICH. }\end{array}$ \\
\hline Rebello et $a l^{45}$ & 73 (all DOAC) & $5(7 \%)$ & $\begin{array}{l}142 \text { (VKA) and } \\
1052 \text { no anticoagulation) }\end{array}$ & $\begin{array}{l}13(9 \%) \text { and } \\
57(5 \%)\end{array}$ & $\begin{array}{l}\text { No selection criteria or information on } \\
\text { anticoagulation available. }\end{array}$ \\
\hline Purrucker et $a l^{44}$ & 28 (all DOAC) & $1(4 \%)$ & NA & & $\begin{array}{l}\text { Drug-specific coagulation tests indicated } \\
\text { through drug concentrations in the majority of } \\
\text { patients, no comparator. }\end{array}$ \\
\hline Zapata-Wainberg et al & 9 (all DOAC) & $0(0 \%)$ & $\begin{array}{l}104 \text { (VKA) and } \\
389 \text { (no anticoagulation) }\end{array}$ & $\begin{array}{l}4(4 \%) \text { and } \\
28(7 \%)\end{array}$ & $\begin{array}{l}\text { No selection criteria or information on } \\
\text { anticoagulation available. }\end{array}$ \\
\hline Kurowski et al & 16 (all DOAC) & $0(0 \%)$ & $\begin{array}{l}51 \text { (VKA) and } \\
453 \text { (no anticoagulation) }\end{array}$ & $\begin{array}{l}7(14 \%) \text { and } \\
32(7 \%)\end{array}$ & $\begin{array}{l}\text { No selection criteria or information on } \\
\text { anticoagulation available. }\end{array}$ \\
\hline Suzuki et al ${ }^{10}$ & 44 (all DOAC) & $3(7 \%)$ & $\begin{array}{l}7 \text { (VKA) and } \\
23 \text { (no anticoagulation) }\end{array}$ & $\begin{array}{l}0(0 \%) \text { and } \\
0(0 \%)\end{array}$ & $\begin{array}{l}\text { No selection criteria or information on } \\
\text { anticoagulation available, recall bias. }\end{array}$ \\
\hline Cernik et al & 15 (not specified) & $0(0 \%)$ & $\begin{array}{l}50 \text { (VKA) and } \\
615 \text { (no anticoagulation) }\end{array}$ & $\begin{array}{l}6(12 \%) \text { and } \\
31(5 \%)\end{array}$ & $\begin{array}{l}\text { No selection criteria or information on } \\
\text { anticoagulation available. }\end{array}$ \\
\hline Hoyer et al & 10 (not specified) & $0(0 \%)$ & 30 (no anticoagulation) & $1(3 \%)$ & $\begin{array}{l}\text { No selection criteria or information on } \\
\text { anticoagulation available. }\end{array}$ \\
\hline Wong et $a l^{43}$ & 13 (all DOAC) & $0(0 \%)$ & $\begin{array}{l}23 \text { (VKA) and } \\
66 \text { (no anticoagulation) }\end{array}$ & $\begin{array}{l}1(4 \%) \text { and } \\
1(2 \%)\end{array}$ & $\begin{array}{l}\text { No selection criteria or information on } \\
\text { anticoagulation available. }\end{array}$ \\
\hline Krajickova et al & 5 (all DOAC) & $0(0 \%)$ & $\begin{array}{l}21 \text { (VKA) and } \\
259 \text { (no anticoagulation) }\end{array}$ & $\begin{array}{l}2(10 \%) \text { and } \\
21(8 \%)\end{array}$ & $\begin{array}{l}\text { No selection criteria or information on } \\
\text { anticoagulation available. }\end{array}$ \\
\hline Meinel et al & 98 (all DOAC) & $5(5 \%)$ & $\begin{array}{l}69 \text { (VKA) and } \\
1612 \text { (no anticoagulation) }\end{array}$ & $\begin{array}{l}5(7 \%) \text { and } \\
84(5 \%)\end{array}$ & $\begin{array}{l}\text { See below for patients with confirmed } \\
\text { therapeutic DOAC therapy only. }\end{array}$ \\
\hline 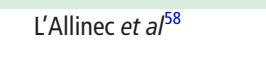 & 105 (all DOAC) & $6(6 \%)$ & 97 (VKA) & $12(12 \%)$ & $\begin{array}{l}\text { Last intake within } 24 \text { hours, specific drug } \\
\text { levels not available. }\end{array}$ \\
\hline Goldhoorn et al & 98 (not specified) & $1(1 \%)$ & $\begin{array}{l}404 \text { (VKA) and } \\
2660 \text { (no anticoagulation) }\end{array}$ & $\begin{array}{l}23(6 \%) \text { and } \\
162(6 \%)\end{array}$ & $\begin{array}{l}\text { No selection criteria or information on } \\
\text { anticoagulation available. }\end{array}$ \\
\hline \multicolumn{6}{|c|}{ DOAC plasma-level based approach ( $\mathrm{n}=2$ studies, $\mathrm{n}=56$ (patients)) } \\
\hline Seiffge et $a l^{28}$ & 7 (rivaroxaban) & $0(0 \%)$ & NA & & 3 of 7 low or intermediate drug level \\
\hline Meinel et $a l^{48}$ & 49 (all DOAC) & $2(4 \%)$ & $\begin{array}{l}222 \text { (VKA) and } \\
1612 \text { (no anticoagulation) }\end{array}$ & $\begin{array}{l}21(9.5 \%) \text { and } \\
84(5 \%)\end{array}$ & $\begin{array}{l}\text { Ascertained compliance or therapeutic drug } \\
\text { levels }\end{array}$ \\
\hline
\end{tabular}

DOAC, direct oral anticoagulant; $\mathrm{PH}$, parenchymal haemorrhage; VKA, vitamin $\mathrm{K}$ antagonist.

other available approaches-using time since last intake and DOAC monitoring-seem to provide equally safety results.

Third, DOAC patients managed with IVT beyond the standard time thrombolysis window need to be explored. Fourth, although tenecteplase is not currently licensed for treatment of ischaemic stroke, several centres have reported off-label use of tenecteplase but experience of tenecteplase with DOAC pretreatment is limited. ${ }^{37}$

\section{CONCLUSION}

This review summarises current knowledge on recanalisation therapies for acute ischaemic stroke therapy in patients taking DOACs. Available data of $>450$ patients receiving IVT and $>550$ patients receiving mechanical thrombectomy provided reassuring safety results although only from observational studies and case reports and not randomised controlled trials. The use of IVT in patients with relative contraindications (eg, prior VKA therapy, ${ }^{5960}$ dual antiplatelet therapy ${ }^{6162}$ or epileptic seizures at onset $^{63}$ has been studied with a focus on safety rather than efficacy, probably due to an overall small effect size of thrombolysis in stroke and the need for large sample sizes to find any effect. We therefore urge caution that safe treatment is not equivalent to efficacy.

Even 10 years after introduction of the first DOAC on the market, there are still a lack of large, multicentre, multinational data with thorough documentation of selection criteria and safety and efficacy outcomes. A randomised controlled trial in the setting of thrombolysis in patients taking DOAC seems very unlikely. The results of large, prospective observational studies like registry of acute stroke under novel oral anticoagulants prime $^{64}$ will hopefully provide further new insights in this topic and additional safety data.

Despite increasing experience and data availability in IVT for DOAC patients, the literature remains relatively limited. The small number of patients likely reflects the intrinsic bias to not treat with thrombolysis in patients on DOACs, and interpretation of the data therefore needs to be considered.

In summary, although available data provide promising and reassuring safety data, several aspects including patient selection need to be addressed in future studies. Precision medicine using a tailored approach combining monitoring anticoagulant activity, imaging-based selection (visualisation of potentially salvageable tissue) with potential use of specific reversal agents seems a reasonable choice in the interim.

\section{REVIEW CRITERIA}

We (DJS, TM, JK, DW and TYW) identified references for this review by searches of PubMed on 1 May 2020, 5 May 2020 and 22 August 2020, using the search terms "(thrombolysis 


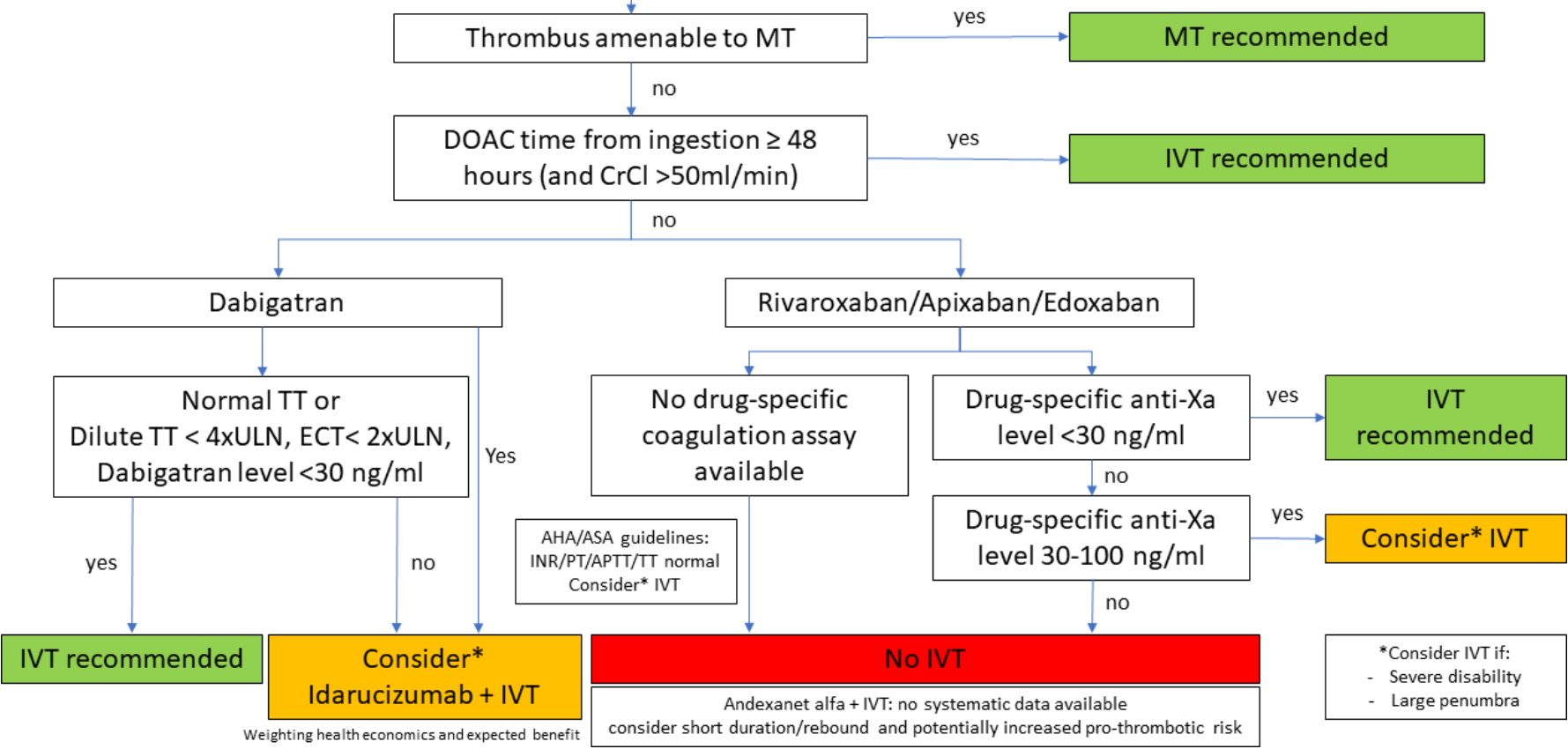

Figure 2 Expert-opinion-based approach for patient selection within the 4.5 hours time window. Decision for intravenous thrombolysis (IVT) should not delay thrombectomy (eg, direct thrombectomy or immediate transfer to a thrombectomy-capable centre recommended). AHA/ASA, American Heart/ Stroke Association; APTT, activated partial thrombin time; DOAC, direct oral anticoagulant; ECT, ecarin clotting time; INR, international normalised ratio; MT, mechanical thrombectomy; PT, prothrombine time; TT, thrombin time; ULN, upper limit normal.

OR IVT OR rtPA OR tPA OR mechanical thrombectomy OR endovascular therapy OR MT OR EVT) AND (DOAC OR rivaroxaban OR dabigatran OR edoxaban OR apixaban OR DOAC OR direct oral anticoagulants OR novel oral anticoagulants OR Non-Vitamin K oral anticoagulants) AND (ischaemic stroke OR ischemic stroke)". One author (DJS) additionally searched EMBASE and Web of science on 12 December 2020. We have excluded Betrixaban from our review due to limited availability outside the US and limited indication label. Additionally, we searched our personal records and abstracts from international conferences in the past 10 years (2010-2020) for relevant publications or data. We selected publications presenting original data and published in English if they reported $\geq 5$ patients on DOACs who received recanalisation therapies. In addition, we searched PubMed, personal records and an internet search engine (ie, Google Scholar) using the search terms "guidelines", "thrombolysis", "stroke" and "oral anticoagulation" OR "DOAC" OR "direct oral anticoagulants" to identify guidelines from relevant organisations (national or international expert committees).

Contributors DJS, DW and TYW: concept of the study. DJS, TM, JK, DW and TYW: first draft of the manuscript. All authors: critical revision of the manuscript for important intellectual content.

Funding The authors have not declared a specific grant for this research from any funding agency in the public, commercial or not-for-profit sectors.

Competing interests DJS: advisory board: Bayer and Pfizer (manufacturer of Rivaroxaban and Apixaban); personal fees used for research funding: Portola (manufacturer of Andexanet alfa). Research funding from the Swiss National Science Foundation, the Bangerter-Rhyner Foundation, the Swiss Society of Neurology and the Bayer Foundation unrelated to the submitted work. JK: Grants from SAMW/ Bangerter, CTU Bern, Swiss Stroke Society. UF: reports other from CSL Behring, Medtronic and Stryker unrelated to the submitted work.

Patient consent for publication Not required.
Provenance and peer review Not commissioned; externally peer reviewed.

Open access This is an open access article distributed in accordance with the Creative Commons Attribution Non Commercial (CC BY-NC 4.0) license, which permits others to distribute, remix, adapt, build upon this work non-commercially, and license their derivative works on different terms, provided the original work is properly cited, appropriate credit is given, any changes made indicated, and the use is non-commercial. See: http://creativecommons.org/licenses/by-nc/4.0/.

\section{ORCID iDs}

David J Seiffge http://orcid.org/0000-0003-3890-3849

Jan Christoph Purrucker http://orcid.org/0000-0003-2978-4972

Johannes Kaesmacher http://orcid.org/0000-0002-9177-2289

Teddy Y Wu http://orcid.org/0000-0003-1845-1769

\section{REFERENCES}

1 Seiffge DJ, De Marchis GM, Koga M, et al. Ischemic stroke despite oral anticoagulant therapy in patients with atrial fibrillation. Ann Neurol 2020;87:677-87.

2 Ebner M, Birschmann I, Peter A, et al. Point-Of-Care testing for emergency assessment of coagulation in patients treated with direct oral anticoagulants. Crit Care 2017;21:32.

3 Powers WJ, Rabinstein AA, Ackerson T, et al. 2018 guidelines for the early management of patients with acute ischemic stroke: a guideline for healthcare professionals from the American heart Association/American stroke association. Stroke 2018;49:e46-110.

4 Turc G, Bhogal P, Fischer U, et al. European Stroke Organisation (ESO) - European Society for Minimally Invasive Neurological Therapy (ESMINT) Guidelines on Mechanical Thrombectomy in Acute Ischaemic StrokeEndorsed by Stroke Alliance for Europe (SAFE). Eur Stroke J 2019;4:6-12.

5 Emberson J, Lees KR, Lyden P, et al. Effect of treatment delay, age, and stroke severity on the effects of intravenous thrombolysis with alteplase for acute ischaemic stroke: a meta-analysis of individual patient data from randomised trials. Lancet 2014;384:1929-35

6 Goyal M, Menon BK, van Zwam WH, et al. Endovascular thrombectomy after large-vessel ischaemic stroke: a meta-analysis of individual patient data from five randomised trials. Lancet 2016;387:1723-31.

7 Yang P, Zhang Y, Zhang L, et al. Endovascular thrombectomy with or without intravenous alteplase in acute stroke. N Engl J Med 2020;382:1981-93. 
8 Purrucker JC, Haas K, Rizos T, et al. Coagulation testing in acute ischemic stroke patients taking non-vitamin $\mathrm{K}$ antagonist oral anticoagulants. Stroke 2017;48:152-8.

9 Rizos T, Herweh C, Jenetzky E, et al. Point-Of-Care international normalized ratio testing accelerates thrombolysis in patients with acute ischemic stroke using oral anticoagulants. Stroke 2009;40:3547-51.

10 Suzuki K, Aoki J, Sakamoto Y, et al. Low risk of ICH after reperfusion therapy in acute stroke patients treated with direct oral anti-coagulant. J Neurol Sci 2017;379:207-11.

11 Seiffge DJ, Hooff R-J, Nolte CH, et al. Recanalization therapies in acute ischemic stroke patients: impact of prior treatment with novel oral anticoagulants on bleeding complications and outcome. Circulation 2015;132:1261-9.

12 Xian Y, Federspiel JJ, Hernandez AF, et al. Use of intravenous recombinant tissue plasminogen activator in patients with acute ischemic stroke who take non-vitamin $\mathrm{K}$ antagonist oral anticoagulants before stroke. Circulation 2017;135:1024-35.

13 Tsivgoulis G, Safouris A. Intravenous thrombolysis in acute ischemic stroke patients pretreated with non-vitamin $\mathrm{K}$ antagonist oral anticoagulants: an editorial review. Stroke 2017:48:2031-3.

14 Shahjouei S, Tsivgoulis G, Bavarsad Shahripour R, et al. Safety of Intravenous Thrombolysis among Stroke Patients Taking New Oral Anticoagulants--Case Series and Systematic Review of Reported Cases. J Stroke Cerebrovasc Dis 2015;24:2685-93.

15 Powers WJ, Rabinstein AA, Ackerson T, et al. Guidelines for the early management of patients with acute ischemic stroke: 2019 update to the 2018 guidelines for the early management of acute ischemic stroke: a guideline for healthcare professionals from the American heart Association/American stroke association. Stroke 2019:50:STR0000000000000211.

16 Liebner S, Dijkhuizen RM, Reiss Y, et al. Functional morphology of the blood-brain barrier in health and disease. Acta Neuropathol 2018;135:311-36.

17 Chen B, Cheng Q, Yang K, et al. Thrombin mediates severe neurovascular injury during ischemia. Stroke 2010;41:2348-52.

18 Lyden P, Pereira B, Chen B, et al. Direct thrombin inhibitor Argatroban reduces stroke damage in 2 different models. Stroke 2014;45:896-9.

19 Barreto AD, Ford GA, Shen L, et al. Randomized, multicenter trial of ARTSS-2 (Argatroban with recombinant tissue plasminogen activator for acute stroke). Stroke 2017:48:1608-16.

20 Spyropoulos AC. Investigational treatments of venous thromboembolism. Expert Opin Investig Drugs 2007;16:431-40.

21 Pfeilschifter W, Spitzer D, Pfeilschifter J, et al. Warfarin anticoagulation exacerbates the risk of hemorrhagic transformation after rt-PA treatment in experimental stroke: therapeutic potential of PCC. PLoS One 2011;6:e26087.

22 Sun L, Zhou W, Ploen R, et al. Anticoagulation with dabigatran does not increase secondary intracerebral haemorrhage after thrombolysis in experimental cerebra ischaemia. Thromb Haemost 2013;110:153-61.

23 Pfeilschifter W, Bohmann F, Baumgarten P, et al. Thrombolysis with recombinant tissue plasminogen activator under dabigatran anticoagulation in experimental stroke. Ann Neurol 2012:71:624-33.

24 Drouet L, Bal Dit Sollier C, Steiner T, et al. Measuring non-vitamin K antagonist oral anticoagulant levels: when is it appropriate and which methods should be used? Int $J$ Stroke 2016;11:748-58.

25 Gosselin RC, Adcock DM, Bates SM, et al. International Council for standardization in haematology (ICSH) recommendations for laboratory measurement of direct oral anticoagulants. Thromb Haemost 2018;118:437-50.

26 Samuelson BT, Cuker A, Siegal DM, et al. Laboratory assessment of the anticoagulant activity of direct oral anticoagulants: a systematic review. Chest 2017;151:127-38.

27 Steiner T, Böhm M, Dichgans M, et al. Recommendations for the emergency management of complications associated with the new direct oral anticoagulants (DOACs), apixaban, dabigatran and rivaroxaban. Clin Res Cardiol 2013;102:399-412.

28 Seiffge DJ, Traenka C, Polymeris AA, et al. Intravenous thrombolysis in patients with stroke taking rivaroxaban using drug specific plasma levels: experience with a standard operation procedure in clinical practice. J Stroke 2017;19:347-55.

29 Seiffge DJ, Traenka C, Gensicke H, et al. Intravenous thrombolysis in stroke patients receiving rivaroxaban. Eur J Neurol 2014;21:e3-4.

30 Ebner M, Peter A, Spencer C, et al. Point-Of-Care testing of coagulation in patients treated with non-vitamin K antagonist oral anticoagulants. Stroke 2015;46:2741-7.

31 Favaloro EJ, Bonar R, Butler J, et al. Laboratory testing for the new oral anticoagulants: a review of current practice. Pathology 2013;45:435-7.

32 Zantek ND, Hayward CP, Simcox TG, et al. An assessment of the state of current practice in coagulation laboratories. Am J Clin Pathol 2016;146:378-83.

33 Meinel TR, Branca M, De Marchis GM, et al. Prior anticoagulation in patients with ischemic stroke and atrial fibrillation. Ann Neurol 2021;89:42-53.

34 Shahjouei S, Tsivgoulis G, Goyal N, et al. Safety of intravenous thrombolysis among patients taking direct oral anticoagulants: a systematic review and meta-analysis. Stroke 2020;51:533-41.

35 Barber PA, Wu TY, Ranta A. Stroke reperfusion therapy following dabigatran reversal with idarucizumab in a national cohort. Neurology 2020;94:e1968-72.

36 Dias FA, Pontes-Neto OM, Seiffge DJ. Idarucizumab before reperfusion therapy in stroke patients on dabigatran: no more cold sweat. Neurology 2020;94:811-2.

37 Beharry J, Waters MJ, Drew R, et al. Dabigatran reversal before intravenous tenecteplase in acute ischemic stroke. Stroke 2020:51:Strokeaha119028327:1616-9.
38 Toyoda K, Yamagami H, Koga M. Consensus guides on stroke thrombolysis for anticoagulated patients from Japan: application to other populations. J Stroke 2018;20:321-31.

39 Jin C, Huang RJ, Peterson ED, et al. Intravenous tPA (tissue-type plasminogen activator) in patients with acute ischemic stroke taking non-vitamin $\mathrm{K}$ antagonist oral anticoagulants preceding stroke. Stroke 2018;49:2237-40.

40 Touzé E, Gruel Y, Gouin-Thibault I, et al. Intravenous thrombolysis for acute ischaemic stroke in patients on direct oral anticoagulants. Eur J Neurol 2018;25:747-52.

41 Seiffge DJ, Kägi G, Michel P, et al. Rivaroxaban plasma levels in acute ischemic stroke and intracerebral hemorrhage. Ann Neurol 2018;83:451-9.

42 Gong IY, Kim RB. Importance of pharmacokinetic profile and variability as determinants of dose and response to dabigatran, rivaroxaban, and apixaban. Can J Cardiol 2013;29:S24-33.

43 Wong JWP, Churilov L, Dowling R, et al. Safety of endovascular thrombectomy for acute ischaemic stroke in anticoagulated patients ineligible for intravenous thrombolysis. Cerebrovasc Dis 2018;46:193-9.

44 Purrucker JC, Wolf M, Haas K, et al. Safety of endovascular thrombectomy in patients receiving non-vitamin K antagonist oral anticoagulants. Stroke 2016;47:1127-30.

45 Rebello LC, Haussen DC, Belagaje S, et al. Endovascular treatment for acute ischemic stroke in the setting of anticoagulation. Stroke 2015;46:3536-9.

46 Marsch A, Macha K, Siedler G, et al. Direct oral anticoagulant plasma levels for the management of acute ischemic stroke. Cerebrovasc Dis 2019;48:17-25.

47 Seiffge DJ, Traenka C, Polymeris A, et al. Feasibility of rapid measurement of rivaroxaban plasma levels in patients with acute stroke. J Thromb Thrombolysis 2017;43:112-6.

48 Meinel TR, Kniepert JU, Seiffge DJ, et al. Endovascular stroke treatment and risk of intracranial hemorrhage in anticoagulated patients. Stroke 2020;51:892-8.

49 Connolly SJ, Crowther M, Eikelboom JW, et al. Full study report of Andexanet alfa for bleeding associated with factor Xa inhibitors. N Engl J Med 2019;380:1326-35.

50 Pollack CV, Reilly PA, Eikelboom J, et al. Idarucizumab for dabigatran reversal. $N$ Engl J Med 2015;373:511-20

51 Lu G, Conley PB, Leeds JM, et al. A phase 2 PK/PD study of andexanet alfa for reversal of rivaroxaban and edoxaban anticoagulation in healthy volunteers. Blood $A d v$ 2020;4:728-39.

52 Kermer P, Eschenfelder CC, Diener H-C, et al. Antagonizing dabigatran by idarucizumab in cases of ischemic stroke or intracranial hemorrhage in GermanyUpdated series of 120 cases. Int I Stroke 2020;15:609-18.

53 Pretnar Oblak J, Sabovic M, Frol S. Intravenous thrombolysis after Idarucizumab application in acute stroke Patients-A potentially increased sensitivity of thrombi to lysis? J Stroke Cerebrovasc Dis 2019;28:768-73.

54 Küpper C, Feil K, Klein M, et al. Idarucizumab administration in emergency situations: the Munich registry of reversal of Pradaxa $\Theta$ in clinical routine (Mr repair). J Neurol 2019;266:2807-11.

55 Šaňák D, Jakubiček S, Černík D, et al. Intravenous thrombolysis in patients with acute ischemic stroke after a reversal of dabigatran anticoagulation with Idarucizumab: a real-world clinical experience. J Stroke Cerebrovasc Dis 2018:27:2479-83.

56 Fang C-W, Tsai Y-T, Chou P-C, et al. Intravenous thrombolysis in acute ischemic stroke after Idarucizumab reversal of dabigatran effect: analysis of the cases from Taiwan. J Stroke Cerebrovasc Dis 2019;28:815-20.

57 Kallmünzer B, Pott M, Schwab S. Letter by Kallmünzer et al Regarding Article, "Safety of Intravenous Thrombolysis Among Patients Taking Direct Oral Anticoagulants: a Systematic Review and Meta-Analysis". Stroke 2020;51:e130-1.

58 L'Allinec V, Sibon I, Mazighi M, et al. MT in anticoagulated patients: direct oral anticoagulants versus vitamin K antagonists. Neurology 2020;94:e842-50

59 Mazya MV, Lees KR, Markus R, et al. Safety of intravenous thrombolysis for ischemic stroke in patients treated with warfarin. Ann Neurol 2013;74:266-74.

60 Xian Y, Liang L, Smith EE, et al. Risks of intracranial hemorrhage among patients with acute ischemic stroke receiving warfarin and treated with intravenous tissue plasminogen activator. JAMA 2012;307:2600-8.

61 Tsivgoulis G, Katsanos AH, Mavridis D, et al. Intravenous thrombolysis for ischemic stroke patients on dual antiplatelets. Ann Neurol 2018;84:89-97.

62 Tsivgoulis G, Katsanos AH, Zand R, et al. Antiplatelet pretreatment and outcomes in intravenous thrombolysis for stroke: a systematic review and meta-analysis. J Neurol 2017; 264:1227-35.

63 Polymeris AA, Curtze S, Erdur $\mathrm{H}$, et al. Intravenous thrombolysis for suspected ischemic stroke with seizure at onset. Ann Neurol 2019;86:770-9.

64 Haas K, Purrucker JC, Rizos T, et al. Rationale and design of the registry of acute stroke under novel oral Anticoagulants-prime (RASUNOA-prime). Eur Stroke $J$ 2019;4:181-8

65 Powers WJ, Rabinstein AA, Ackerson T, et al. Guidelines for the early management of patients with acute ischemic stroke: 2019 update to the 2018 guidelines for the early management of acute ischemic stroke: a guideline for healthcare professionals from the American heart Association/American stroke association. Stroke 2019;50:e344-418

66 Ahmed N, Audebert $\mathrm{H}$, Turc $\mathrm{G}$, et al. Consensus statements and recommendations from the ESO-Karolinska stroke update Conference, Stockholm 11-13 November 2018. Eur Stroke J 2019:4:307-17. 